\title{
Heat transfer enhancement for spent nuclear fuel assembly disposal packages using metallic void fillers: A prevention technique for solidification shrinkage-induced interfacial gaps
}

\author{
Yongsoo Park*, Thomas J. McKrell, and Michael J. Driscoll \\ *Correspondence: yspark@alum.mit.edu \\ Department of Nuclear Science and Engineering, Massachusetts Institute of Technology. \\ 77 Massachusetts Ave., Cambridge, MA 02139, USA.
}

\begin{abstract}
This study considers replacing the externally accessible void spaces inside a disposal package containing a spent nuclear fuel assembly (SNFA) with high heat conducting metal to increase the effective thermal conductivity of the package and simplify the heat transfer mechanism inside the package by reducing it to a conduction dominant problem. The focus of the study is on preventing the gaps adjacent to the walls of the package components, produced by solidification shrinkage of poured liquid metal. We approached the problem by providing a temporary coating layer on the components to avoid direct build-up of thick metal oxides on their surface to promote metallic bonding at the interfaces under a non-inert environment. Laboratory scale experiments without SNFA were performed with Zn coated low carbon steel canisters and Zamak-3 void filler under two different filling temperature conditions - below and above the melting point of $\mathrm{Zn}$ (designated BMP and AMP respectively). Gap formation was successfully prevented in both cases while we confirmed an open gap in a control experiment, which used an uncoated canister. Minor growth of Al-Fe intermetallic phases was observed at the canister/filler interface of the sample produced under the BMP condition while their growth was significant and showed irregularly distributed morphology in the sample produced under the AMP condition, which has a potential to mitigate excessive residual stresses caused by shrinkage prevention. A procedure for the full-scale application was specified based on the results.
\end{abstract}

Keywords: Spent nuclear fuels, decay heat removal, metallic void filler, gap prevention 


\section{Introduction}

This study considers replacing the externally accessible void spaces inside a disposal package containing a spent nuclear fuel assembly (SNFA), e.g., the space between the canister and the SNFA, and the space within the SNFA such as the coolant channels, with high heat conducting metal. Its successful implementation can lead to increased effective thermal conductivity of the package and simplify the heat transfer mechanism inside the package by reducing it to a conduction dominant problem, besides other benefits such as providing structural support to the canister, enhancing radionuclides retention, stabilizing the SNFA during transportation and emplacement, and increasing the complexity of SNFA retrieval - a safeguards feature. These benefits are especially suitable for packages containing SNFAs from once through breed and burn type reactors, such as the Traveling Wave Reactor [1], as they are expected to have high decay heat with high peak to average ratio, and are not subjected to reprocessing.

Considering the complex geometry of SNFAs, a straightforward way to fill the void spaces is to heat the package components, e.g., the canister and the SNFA, pour in liquid metal, and cool the system down to solidify the liquid metal. Hereafter, the added metal is referred to as (void) filler and the process is referred to as (void) filling process. This was previously investigated by Mathew and co-workers in the 1980s [2-5] where they applied the concept to package CANDU reactor SNFAs. Their studies considered aluminum, zinc, lead, and their based alloys as void filler. More recently, a similar concept was proposed by Gibb and co-workers [6] where fine lead particulates were filled into canisters. Their concept used the decay heat from SNFAs to melt the particulates at the initial stage of geologic waste emplacement where temperature increases due to poor heat transfer through the host rock, later followed by solidification of the molten metal as decay heat decreases with time. These processes, however, can produce defects in the void filler as most metals shrink during solidification which limits fully achieving the heat transfer benefits. Formation of large defects such as internal cavities can be mitigated by directional cooling, and porosity can be controlled by using an alloy as a void filler [7]. Yet, prevention techniques for the gap formation at interfaces between solid structures and solidifying liquid metal, which are applicable to the SNFA packaging process, were not extensively investigated. Efforts were made to model or measure the thickness of the gap and the heat transfer coefficient through the gap for simple mold geometries [8-11], however, predicting these parameters in a canister containing a significantly deformed SNFA can be challenging due to its uncertain geometrical status. Mathew and co-workers also studied the heat transfer mechanism through the gaps using simple mold geometries without the presence of SNFAs [5].

This study was therefore aimed at developing a technique to prevent interfacial gap formation. The key is to promote metallic bonding between the void filler and the package components. However, iron and carbon steels are considered as potential materials for a disposal canister [12] or an internal 
support provider [13], and the oxidation rates of these materials at elevated temperatures are known to be high [14]. The package components should be preheated to prevent early solidification of the liquid metal, and this will produce a thick oxide layer, inhibiting the metallic bonding. The present study assumes conducting the void filling process under an inert environment is not a viable option. Instead, the problem is addressed by coating the selected surfaces of the package components with a slowly oxidizing metal to provide a temporary layer, which oxidizes instead of the coated body during the preheating stage. The idea was tested through a laboratory-scale experiment without SNFA, and an example procedure is proposed for full-scale application based on the experimental observations.

\section{Material and Methods}

\subsection{Materials}

Several criteria should be considered while selecting a void filler. A detailed discussions of their requirements can be found elsewhere [15]. Considering the requirements, with a focus on physical properties such as melting point and thermal conductivity, cost, and the amount of available information in the literature, a Zn-Al alloy was used in this study. Specifically, we used the Zamak-3 alloy, which was also one of the materials tested in the studies by Mathew and co-workers [2]. Hereafter, this alloy is referred as $\mathrm{Zn}-4 \mathrm{Al}$, neglecting the minor alloying elements in the notation for convenience. Low carbon steel (AISI 1026) was used for the canister and Zn was used for the coating to minimize the number of elements introduced to the system. The canisters used in the experiment had an outer diameter of 50.8 $\mathrm{mm}$ ( 2 inch), wall thickness of $1.651 \mathrm{~mm}$ (0.065 inch), and height of $101.6 \mathrm{~mm}$ (4.0 inch). The canisters were coated with $\mathrm{Zn}$ following the conventional dry hot dip galvanization process [16]. Specifically, they were degreased and pickled, fluxed with $500 \mathrm{~g} / \mathrm{L} \mathrm{ZnCl}_{2} / \mathrm{NH}_{4} \mathrm{Cl}\left(25: 75\right.$ wt.\%) salt solution at $80{ }^{\circ} \mathrm{C}$ for 3 minutes, dried at $120{ }^{\circ} \mathrm{C}$ for 3 minutes in air, and immersed into liquid $\mathrm{Zn}$ with 99.5 wt.\% purity. The temperature of the liquid was kept around $450{ }^{\circ} \mathrm{C}$ and the immersion time was 3 minutes. A scanning electron microscope (SEM) image near the canister/coating interface is shown in Figure 1. The coating consists of a thin layer of $\mathrm{Zn}-\mathrm{Fe}$ intermetallic phases (Zn-Fe phases hereafter) at the interface, followed by a thick layer of $\mathrm{Zn}$ at the outer region.

\subsection{Experimental}




\subsubsection{Heating/Cooling Apparatus}

A custom designed heating/cooling apparatus was prepared for the experiment. A schematic of the apparatus is shown in Figure 2-(a). It consisted of a cooling chamber with one inlet and two outlets for water flow. These pipes passed through a thick layer of thermal insulation. The top of the chamber had a socket, and a copper chill block was plugged into it to promote directional solidification from the bottom. The head of the block, where the tube was assembled, was coated with graphite to prevent adhesion of the void filler. The block was replaced after every experiment. A cylindrical radiant heater surrounded the chamber with marginal height to cover the height of the canister. A thermal insulation lid with a pouring spout rested on the top of the heater. Three K-type thermocouples were spot-welded to the outer wall of each canister, axially equidistant to each other, to monitor the temperature of the liquid metal and control the heater power during the experiment. We confirmed the negligible difference between the outer wall temperature and the liquid metal temperature at each axial position.

\subsubsection{Experimental procedure and test matrix}

The experiment was conducted based on the following procedure and the test matrix shown in Table 1. Two temperature conditions, i.e., below-melting-point-of-Zn (BMP) and above-melting-point-of-Zn (AMP), were considered in the void filling process. Test 3 in Table 1 was meant to confirm the gap formation at the canister/filler interface under the absence of the coating.

A. The apparatus was heated up until the top thermocouple started to measure around $400{ }^{\circ} \mathrm{C}$, which is $20^{\circ} \mathrm{C}$ lower than the melting point of $\mathrm{Zn}$ and $13{ }^{\circ} \mathrm{C}$ higher than the liquidus temperature of $\mathrm{Zn}$ 4Al. The heater power was kept constant at this step. This step required about 30 minutes for the apparatus.

B. The heater power was controlled to increase the temperatures at the other two axial positions while keeping the top temperature around $400{ }^{\circ} \mathrm{C}$. The temperature increase rate varied at each axial position as the bottom part was connected to the cooling chamber. This step required approximately 30 minutes for this apparatus. We were also allowing the coating (or the canister, in Test 3) to oxidize at this step. Step A and B are referred to as preheating stage hereafter.

C. Liquid $\mathrm{Zn}-4 \mathrm{Al}$ was poured into the canister through the pour spout. The liquid was prepared to match the temperature for the next step.

D. The heater power was controlled to keep the void filler as liquid for 10 minutes at each filling temperature shown in Table 1. Note that the liquidus temperature of $\mathrm{Zn}-4 \mathrm{Al}$ is below $400{ }^{\circ} \mathrm{C}$. 
E. The heater was turned off and water cooling through the copper chill block started. This forces the solidification front to move uni-directionally upward from the bottom.

The measured temperature profile from each test is shown in Figure 2-(b) with alphabetical headings denoting each step in the experimental procedure. After each test, the canister containing $\mathrm{Zn}-4 \mathrm{Al}$ was disassembled and sectioned at the axial position of the top and the middle thermocouples, and the surfaces were polished for microscopic inspection. For convenience, the samples from Test 1, 2, and 3 are designated as S-BMP, S-AMP, and S-CTL, respectively.

\section{Results}

Figure 2-(c) shows pictures near the canister/filler interface of the samples from each test. Both S-BMP and S-AMP had no gaps at the interface while S-CTL had an open gap. An approximated comparison of the effective thermal conductivity between S-AMP and S-CTL can be found in our earlier study [17] where closing the gap increased its value by a factor of six under the experimental conditions used in the study.

Backscattered scanning electron microscope images (BSEM) taken at the interface of S-BMP and S-AMP are shown in Figure 3 and Figure 4, respectively. Composition analysis was performed at several points of interest in the two samples using point energy dispersive X-ray spectroscopy (EDX). The results from S-BMP and S-AMP are listed in Table 2 and Table 3, respectively. The dark areas in the BSEM images were rich in $\mathrm{Al}$ and $\mathrm{Fe}$ with minor composition of $\mathrm{Zn}$. These phases are referred as $\mathrm{Al}-\mathrm{Fe}$ phases hereafter. The ratio of $\mathrm{Al}$ to $\mathrm{Fe}$ at each point in the two samples is also included in the tables. The ratio tended to increase towards the interior in S-AMP. The amount of Al-Fe phases formed in S-BMP and SAMP was significantly different. Note the difference in magnification among the BSEM images.

\section{Discussion}

\subsection{Discussion of the results}

The temperature conditions during the preheating stage (step A and B) in the experimental procedure allows the growth of $\mathrm{Zn}$-Fe phases via solid state diffusion of which the process is often called galvannealing. Kinetics studies that measured the thickness of the $\mathrm{Zn}-\mathrm{Fe}$ phase layers as a function of 
annealing time are available in the literature at $400{ }^{\circ} \mathrm{C}[18,19]$ and at lower temperatures [20], and their results do not show clearly definable growth rates. This leads to spatial variation in the overall thickness of the $\mathrm{Zn}-\mathrm{Fe}$ phases, especially due to the temperature variation in the axial direction during the preheating stage. Moreover, the thickness of the $\mathrm{Zn}$ coating layer is sensitive to the temperature of the galvanizing bath and immersion time [21], in addition to the composition of the steel substrate and the bath. For these reasons, it is uncertain to determine the remaining thickness of the $\mathrm{Zn}$ layer in the coating after the preheating stage unless its duration is significantly short or long, which is not considered here as preheating an actual canister can take several minutes while minimizing the duration can be desired. However, the $\mathrm{Zn}$ layer provides a diffusion barrier to oxygen for reaching the canister or the $\mathrm{Zn}$-Fe phases as far as it lasts while $\mathrm{Zn}$ itself has low oxidation rate [22]. Consequently, the canister and the void filler could metallically bond in S-BMP and S-AMP within the given reaction time in step D while S-CTL could not.

The BSEM images of S-BMP (Figure 3) shows no trace of $\mathrm{Zn}$ or the $\mathrm{Zn}-\mathrm{Fe}$ phases, which was observed in the as-produced coating (Figure 1), but rather shows large Zn-rich grains, lamella structure of $\mathrm{Zn}$-rich and $\mathrm{Al}$-rich grains, and $\mathrm{Al}-\mathrm{Fe}$ phases near the interface. This indicates the Al contents in liquid $\mathrm{Zn}-4 \mathrm{Al}$ was able to diffuse through the solid coating during the 10 minutes of step $\mathrm{D}$ in the experimental procedure and some of them transformed the $\mathrm{Zn}$-Fe phases into Al-Fe phases, as the latter are known to be thermodynamically more stable [23]. In commercial hot dip galvanizing where around $2 \mathrm{wt} \%$ of $\mathrm{Al}$ is added into $\mathrm{Zn}, \mathrm{Al}-\mathrm{Fe}$ phases are first formed at the steel/liquid interface and later they transform into $\mathrm{Zn}$ Fe phases due to the low composition of $\mathrm{Al}$ in the galvanizing bath [24,25]. This is known to delay the loss of $\mathrm{Fe}$ from the steel as additional $\mathrm{Fe}$ is not needed during transformation [16]. Analogously, the $\mathrm{Zn}$ Fe to Al-Fe phase transformation could reduce the loss of Fe from the canister during step D. The increased width of the region where the Al-Fe phases are observed in Figure 3 compared to that where the $\mathrm{Zn}$-Fe phases are observed in Figure 1 is more likely to be caused by the further growth of the $\mathrm{Zn}-\mathrm{Fe}$ phases during the preheating stage, providing more phases to be transformed, rather than caused by forming more Al-Fe phases with additional Fe from the canister. Note that the further growth of the Al-Fe phases should occur both towards the canister and towards the void filler, which gives Al-Fe phases adjacent to the canister a lower composition of $\mathrm{Al}$, such as those observed in S-AMP, i.e., points A and B in Figure 4. These phases were not observed in S-BMP.

Increased amount of the Al-Fe phases was observed in S-AMP. In addition to the increased reaction kinetics due to the higher temperature condition during step $\mathrm{D}$, the AMP condition allowed any remaining solid $\mathrm{Zn}$ in the coating, which was not transformed into $\mathrm{Zn}$-Fe phases during the preheating stage, to melt, facilitating direct contact between the $\mathrm{Zn}-\mathrm{Fe}$ phases formed on the surface of the canister and the liquid $\mathrm{Zn}-4 \mathrm{Al}$. Similar to S-BMP, the Al-Fe phases would have first formed by transforming the 
$\mathrm{Zn}-\mathrm{Fe}$ phases in the coating, but the AMP condition allowed further formation of Al-Fe phases via additional diffusion of $\mathrm{Fe}$ from the canister and diffusion of $\mathrm{Al}$ from liquid $\mathrm{Zn}-4 \mathrm{Al}$. The $\mathrm{Al}-\mathrm{Fe}$ phases in the BSEM images of S-AMP (Figure 4) show a distributed morphology rather than a layered structure, which seems to be caused by partial detachment of the Al-Fe phases at the boundary of the layer due to their excessive build-up. As they were surrounded by liquid $\mathrm{Zn}-4 \mathrm{Al}$, the liquid motion could carry the detached Al-Fe phases towards the interior of the sample. The increased Al to Fe ratio at point $\mathrm{E}$ in Figure 4 compared to points $\mathrm{C}$ and D indicates that the detachment occurred gradually. Similar morphology was observed in low carbon steels coated with $\mathrm{Zn}-5 \mathrm{wt} . \% \mathrm{Al}$ at $450{ }^{\circ} \mathrm{C}$ [28], but the $\mathrm{Al}-\mathrm{Fe}$ phase with $\mathrm{Al}$ to $\mathrm{Fe}$ ratio of point $\mathrm{E}$ in Figure 4 was not reported, perhaps because it was not included in the coating while the steels were being withdrawn from the bath of liquid metal. Due to the mechanism, the Al-Fe phase layer at the interface will maintain a finite width, allowing continuous growth of the phases. This characteristic is utilized in the full-scale application discussed in the next section (section 4.2).

\subsection{Reduction and segmentation of liquid volume using Al-Fe phases}

Increased volume of liquid metal increases the overall solidification shrinkage. Preventing the gap formation in a large volume of liquid can cause excessive build-up of residual stresses during solidification, which may initiate cracks in the void filler. The sample produced from multi-directionally cooling the liquid void filler, which is shown in our previous study [29], gives an example as cracks were formed in the solidified void filler near the interface while metallic bonding was observed at the canister/filler interface. Adopting the uni-directionally upward cooling technique, any accumulation of residual stresses in the axial direction can be reduced as we are allowing axial shrinkage, and the shrunk volume can be compensated by feeding additional liquid metal from the top. As a result, the stresses will be more dependent on the cross-sectional area normal to the solidification direction.

Figure 5-(A) shows an illustration of the full-scale void filling process. Note that the expected application of the technique introduced in this study is once through breed and burn type reactors where fuel rods are surrounded by a duct wall. Details such as wire wraps and radiation induced deformation are not represented in the figure. The void space inside the duct wall is mainly the narrow coolant channels, which are semi-isolated from each other due to the presence of wire wraps, and therefore, solidification shrinkage will be negligible. However, the cross-sectional area outside the duct wall can be much larger than the samples depending on the temperature profile one desires to obtain inside the package and at the near field of the disposal zone. Packaging multiple assemblies into a single canister can also increase the 
void space outside the duct wall. This may require residual stress mitigation techniques to prevent any crack initiation in the void filler.

The Al-Fe phases in S-AMP (Figure 4) showed a distributed morphology due to their detachment from the interface and liquid motion. Noting that the Al-Fe phases are solid under the temperature conditions in the procedure, promoting their growth, e.g., by increasing the time duration of step D in the experimental procedure, adding pieces of Fe into the liquid void filler, and increasing the liquid motion via agitation, can reduce the area occupied by the liquid per unit height and semi-segment the liquid spaces. This is schematically shown in the last image of Figure 5-(B). Qualitatively, this has the potential of preventing excessive build-up of residual stresses; however, further study is required, and planned, to quantify the effect.

\subsection{A suggested procedure for full-scale application}

The full-scale application introduces SNFA into the system which requires additional considerations in the procedure. Due to the narrow coolant channels in the SNFA, the process of pouring the liquid void filler should precede emplacing the SNFA into the canister. When the liquid void filler is poured after the preheating stage of the canister, the temperature of the liquid should be kept at the BMP condition until the SNFA emplacement is completed to delay the growth of the Al-Fe phases and to retain the phases at the interface, noting that these can interfere with the flow path in the coolant channels during the emplacement. Once the emplacement is completed, the temperature should be increased to the AMP condition to promote the growth of the Al-Fe phases for liquid space reduction and segmentation purposes. However, liquid metal corrosion of the SNFA materials can be a concern as studies have reported notable reactive wetting behavior between liquid $\mathrm{Zn}-\mathrm{Al}$ and stainless steels under contact times from minutes to hours [30,31]. The overall contact time between the SNFA and liquid Zn-Al can be significant depending on the emplacement speed and the amount of Al-Fe phases one desires to grow from the canister and from the added Fe pieces, if any.

As discussed in the previous section, solidification shrinkage depends on the cross-sectional area of the liquid volume which is normal to the cooling direction. Accordingly, the concern of shrinkage mainly goes to the space between the canister and the duct wall while the shrinkage inside the duct wall is likely to be negligible. Oxidized steels can still be coated with $\mathrm{Zn}$ when fluxing agent is added, as minor $\mathrm{Zn}$-Fe phases form wherever the oxide layer becomes destabilized [32]. Oxidizing the SNFA and applying the fluxing agent only to the outer surface of the duct wall will selectively coat the SNFA with $\mathrm{Zn}$. Preheating the SNFA is also required prior to its emplacement into the liquid void filler to prevent 
early solidification. During this step, the $\mathrm{Zn}$ coating will oxidize instead of the outer surface of the duct wall while oxides will continue to build-up on the uncoated surfaces of the SNFA. After emplacement, the mechanism that occurs at the canister/filler interface will occur at the interface between the void filler and the outer surface of the duct wall, and form metallic bonds, while the metal oxides layer suppresses the formation of the intermetallic phases on the other surfaces of SNFA, similar to Test 3 in the experiment. Illustrations of the status near the interfaces of interest is shown in Figure 5-(B), (C), and (D).

\section{Conclusions}

This study considered enhancing the heat transfer inside a spent nuclear fuel assembly disposal package by means of metallic void fillers. The focus was on developing a prevention technique to close the gaps at interfaces formed by solidification shrinkage. Providing a temporary coating layer of $\mathrm{Zn}$ on the selected surfaces of iron/steel package components before the void filling process and using $\mathrm{Zn}-4 \mathrm{Al}$ as a void filler can prevent the formation of the gaps. This technique creates Al-Fe intermetallic phases as a by-product which has a potential of mitigating the excessive build-up of residual stresses as they reduce and segment the volume of the liquid.

Although this study used the Fe-Al-Zn system, other combinations of materials can, in principle, be used for the same procedure as long as the coating material has low oxidation rate, melting point (range) of the void filler is lower than that of the coating material, and if the void filler can form intermetallic phases with the materials comprising the package components.

\section{Acknowledgement}

The work was supported by the Department of Energy Nuclear Engineering University Program and a research contract from TerraPower, LLC. 


\section{References}

[1] P. Hejzlar, R. Petroski, J. Cheatham, N. Touran, M. Cohen, B. Truong, R. Latta, M. Werner, T. Burke, J. Tandy, M. Garrett, B. Johnson, T. Ellis, J. Mcwhirter, A. Odedra, P. Schweiger, D. Adkisson, J. Gilleland, TerraPower, LLC Traveling wave reactor development program overview, Nucl. Eng. Technol. 45 (2013) 731-744. doi:10.5516/NET.02.2013.520.

[2] P.M. Mathew, F. Weinberg, J.S. Nadeau, A.C.D. Chaklader, Filler metals for containers holding irradiated fuel bundles, Met. Technol. 9 (1982) 375-380. doi:10.1179/030716982803286269.

[3] P. Mani Mathew, P.A. Krueger, P.M. Mathew, J.S. Nadeau, F. Weinberg, A.C.D. Chaklader, K. Nuttall, P.M. Mathew, F. Weinberg, J.S. Nadeau, A.C.D. Chaklader, Metal Matrix Integrity and Related Technology Development in the Canadian Nuclear Fuel Waste Management Program, in: MRS Proc., Cambridge University Press, 1983: p. 583. doi:10.1557/PROC-26-583.

[4] P. Mani Mathew, P.A. Krueger, Casting Development for Nuclear Fuel Disposal Containers, Can. Metall. Q. 26 (1987) 37-46. doi:10.1179/cmq.1987.26.1.37.

[5] P.M. Mathew, J.W. Devaal, P.A. Krueger, A Thermal Conduction Model for Heat Flow through Cast Lead and A Water-Cooled Stainless-Steel Container, Can. Metall. Q. 28 (1989) 271-283. doi:10.1179/cmq.1989.28.3.271.

[6] F.G.F. Gibb, N.A. McTaggart, K.P. Travis, D. Burley, K.W. Hesketh, High-density support matrices: Key to the deep borehole disposal of spent nuclear fuel, J. Nucl. Mater. 374 (2008) 370377. doi:10.1016/j.jnucmat.2007.08.017.

[7] H. Fredriksson, U. Åkerlind, Solidification and Cooling Shrinkage of Metals and Alloys, in: Materials Processing During Casting, John Wiley \& Sons, Ltd, Chichester, UK, 2006. doi:10.1002/9780470017920.ch10.

[8] K. Ho, R.D. Pehlke, Metal-Mold interfacial heat transfer, Metall. Trans. B. 16 (1985) 585-594. doi:10.1007/BF02654857.

[9] Y. Nishida, W. Droste, S. Engler, The air-gap formation process at the casting-mold interface and the heat transfer mechanism through the gap, Metall. Trans. B. 17 (1986) 833-844. doi:10.1007/BF02657147.

[10] T. Loulou, E.. Artyukhin, J.. Bardon, Estimation of thermal contract resistance during the first stages of metal solidification process: II-experimental setup and results, Int. J. Heat Mass Transf. 42 (1999) 2129-2142. doi:10.1016/S0017-9310(98)00338-X.

[11] A. Lagerstedt, J. Kron, F. Yosef, Measurements and modeling of air gap formation in iron-base alloys, Mater. Sci. Eng. A. 413 (2005) 44-51. doi:10.1016/j.msea.2005.08.165.

[12] R.B. Rebak, Environmentally Assisted Cracking Research of Engineering Alloys for Nuclear 
Waste Repository Containers, in: MRS Proc., Cambridge University Press, 2012: pp. 449-458. doi:10.1557/opl.2012.615.

[13] L. Werme, Design premises for canister for spent nuclear fuel, SKB Technical Report TR-98-08, Sep. 1998.

[14] R.Y. Chen, W.Y.D. Yeun, Review of the High-Temperature Oxidation of Iron and Carbon Steels in Air or Oxygen, Oxid. Met. 59 (2003) 433-468. doi:10.1023/A:1023685905159.

[15] F. Puig, J. Dies, J. de Pablo, A. Martínez-Esparza, Spent fuel canister for geological repository: Inner material requirements and candidates evaluation, J. Nucl. Mater. 376 (2008) 181-191. doi:10.1016/j.jnucmat.2008.02.069.

[16] A.R. Marder, The metallurgy of zinc-coated steel, Prog. Mater. Sci. 45 (2000) 191-271. doi:10.1016/S0079-6425(98)00006-1.

[17] Y. Park, T.J. McKrell, M.J. Driscoll, Spent Nuclear Fuel Package Consolidation using Metallic Void Fillers, in: Trans. Am. Nucl. Soc., Vol.113, Las Vegas, Nov. 2016: pp. 294-295.

[18] Syahbuddin, P.R. Munroe, C.S. Laksmi, B. Gleeson, Effects of 0.1 and 0.2 wt.\% aluminium addition to zinc on the interdiffusion between zinc and iron at $400^{\circ} \mathrm{C}$, Mater. Sci. Eng. A. 251 (1998) 87-93. doi:10.1016/S0921-5093(98)00641-8.

[19] Syahbuddin, P.. Munroe, B. Gleeson, The development of Fe-Zn intermetallic compounds in solid $\mathrm{Fe} / \mathrm{Zn}$ and $\mathrm{Fe} / \mathrm{Zn}-\mathrm{Al}$ diffusion couples during short-term annealing at $400^{\circ} \mathrm{C}$, Mater. Sci. Eng. A. 264 (1999) 201-209. doi:10.1016/S0921-5093(98)01089-2.

[20] M. Onishi, Y. Wakamatsu, H. Miura, Formation and Growth Kinetics of Intermediate Phases in Fe-Zn Diffusion Couples, Trans. Japan Inst. Met. 15 (1974) 331-337. doi:10.2320/matertrans1960.15.331.

[21] P. Bicao, W. Jianhua, S. Xuping, L. Zhi, Y. Fucheng, Effects of zinc bath temperature on the coatings of hot-dip galvanizing, Surf. Coatings Technol. 202 (2008) 1785-1788. doi:10.1016/j.surfcoat.2007.07.044.

[22] C.D.S. Tuck, M.E. Whitehead, R.E. Smallman, A fundamental study of the kinetics of zinc oxidation in the temperature range $320-415^{\circ} \mathrm{C}$ in atmospheres of pure oxygen and oxygen doped with gaseous impurities, Corros. Sci. 21 (1981) 333-352. doi:10.1016/0010-938X(81)90071-8.

[23] P. Perrot, J.C. Tissier, J.Y. Dauphin, Stable and metastable equilibria in the Fe-Zn-Al system at 450 C, Zeitschrift Für Met. 83 (1992) 786-790.

[24] Y. Adachi, M. Arai, Transformation of $\mathrm{Fe}-\mathrm{Al}$ phase to $\mathrm{Fe}-\mathrm{Zn}$ phase on pure iron during galvanizing, Mater. Sci. Eng. A. 254 (1998) 305-310. doi:10.1016/S0921-5093(97)00840-X.

[25] T. Kato, K. Nunome, K. Kaneko, H. Saka, Formation of the $\zeta$ phase at an interface between an Fe substrate and a molten 0.2 mass\% Al-Zn during galvannealing, Acta Mater. 48 (2000) 2257-2262. 
doi:10.1016/S1359-6454(00)00037-9.

[26] L. Chen, R. Fourmentin, J.R. Mc Dermid, Morphology and Kinetics of Interfacial Layer Formation during Continuous Hot-Dip Galvanizing and Galvannealing, Metall. Mater. Trans. A. 39 (2008) 2128-2142. doi:10.1007/s11661-008-9552-z.

[27] T. Min, Y. Gao, L. Chen, Q. Kang, W.-Q. Tao, Mesoscale investigation of reaction-diffusion and structure evolution during $\mathrm{Fe}-\mathrm{Al}$ inhibition layer formation in hot-dip galvanizing, Int. J. Heat Mass Transf. 92 (2016) 370-380. doi:10.1016/j.ijheatmasstransfer.2015.08.083.

[28] Z.W. Chen, J.T. Gregory, R.M. Sharp, Intermetallic phases formed during hot dipping of low carbon steel in a Zn-5 pct Al melt at $450^{\circ} \mathrm{C}$, Metall. Trans. A. 23 (1992) 2393-2400. doi:10.1007/BF02658042.

[29] Y. Park, T.J. McKrell, M.J. Driscoll, Thermal resistance reduction in cast metal filled used nuclear fuel canisters, in: Trans. Am. Nucl. Soc., Vol.115, Washington D.C., Nov. 2015: pp. 358-359.

[30] K. Zhang, N.Y. Tang, F.E. Goodwin, S. Sexton, Reaction of 316L stainless steel with a galvanizing bath, J. Mater. Sci. 42 (2007) 9736-9745. doi:10.1007/s10853-007-1978-y.

[31] J. Xu, X. Liu, M.A. Bright, J.G. Hemrick, V. Sikka, E. Barbero, Reactive Wetting of an Iron-Base Superalloy MSA2020 and 316L Stainless Steel by Molten Zinc-Aluminum Alloy, Metall. Mater. Trans. A. 39 (2008) 1382-1391. doi:10.1007/s11661-008-9501-x.

[32] C.E. Jordan, A.R. Marder, The effect of iron oxide as an inhibition layer on iron-zinc reactions during Hot-Dip galvanizing, Metall. Mater. Trans. B. 29 (1998) 479-484. doi:10.1007/s11663998-0127-6. 
Table 1. Experimental test matrix.

\begin{tabular}{|l|l|lll|l|}
\hline Test & Zn Coating (y/n) & Filling Temperature & Sample \\
\hline 1 & $\mathrm{y}$ & $\begin{array}{l}\text { BMP } \\
\left.{ }^{\circ} \mathrm{C}\right)\end{array}$ & (around 400 & S-BMP \\
\hline 2 & $\mathrm{y}$ & $\begin{array}{l}\text { AMP } \\
\text { (around }\end{array}$ & 450 & S-AMP \\
\hline 3 & $\mathrm{n}$ & $\begin{array}{l}\text { AMP } \\
\left.{ }^{\circ} \mathrm{C}\right)\end{array}$ & & \\
\hline
\end{tabular}

Table 2. Measured compositions at the points marked on the BSEM images of S-BMP (Figure 3).

\begin{tabular}{|l|l|l|l|l|}
\hline \multirow{2}{*}{ Point } & \multicolumn{2}{|l|}{ Atomic \% } & Al/Fe \\
\cline { 2 - 4 } & $\mathrm{Al}$ & $\mathrm{Fe}$ & $\mathrm{Zn}$ & \\
\hline $\mathrm{A}$ & 70.97 & 25.44 & 3.59 & 2.80 \\
\hline $\mathrm{B}$ & 72.14 & 24.08 & 3.78 & 3.00 \\
\hline
\end{tabular}

Table 3. Measured compositions at the points marked on the BSEM images of S-AMP (Figure 4).

\begin{tabular}{|l|l|l|l|l|}
\hline \multirow{2}{*}{ Point } & \multicolumn{2}{|l|}{ Atomic \% } & Al/Fe \\
\cline { 2 - 4 } & Al & Fe & Zn & \\
\hline A & 66.06 & 24.94 & 9.00 & 2.66 \\
\hline B & 66.54 & 25.49 & 7.97 & 2.62 \\
\hline C & 71.21 & 23.34 & 5.45 & 3.06 \\
\hline D & 71.45 & 23.84 & 4.71 & 3.00 \\
\hline E & 71.45 & 21.43 & 7.12 & 3.34 \\
\hline
\end{tabular}




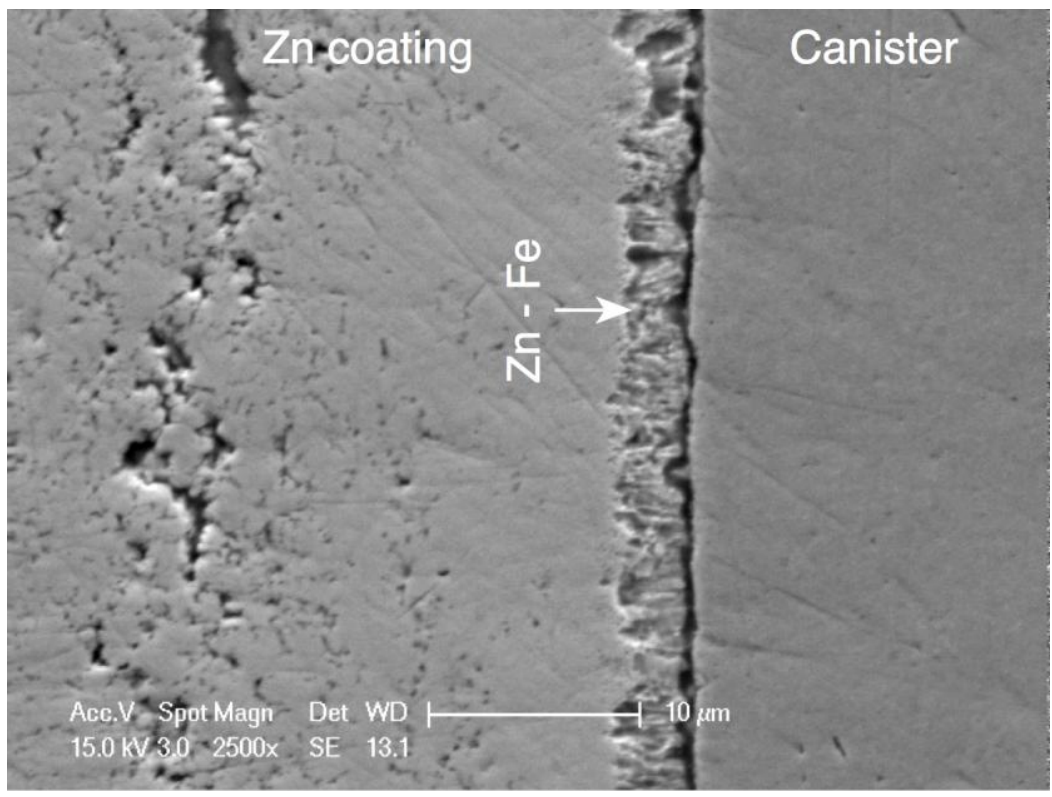

Figure 1. SEM image near the canister/coating interface. 
(a)

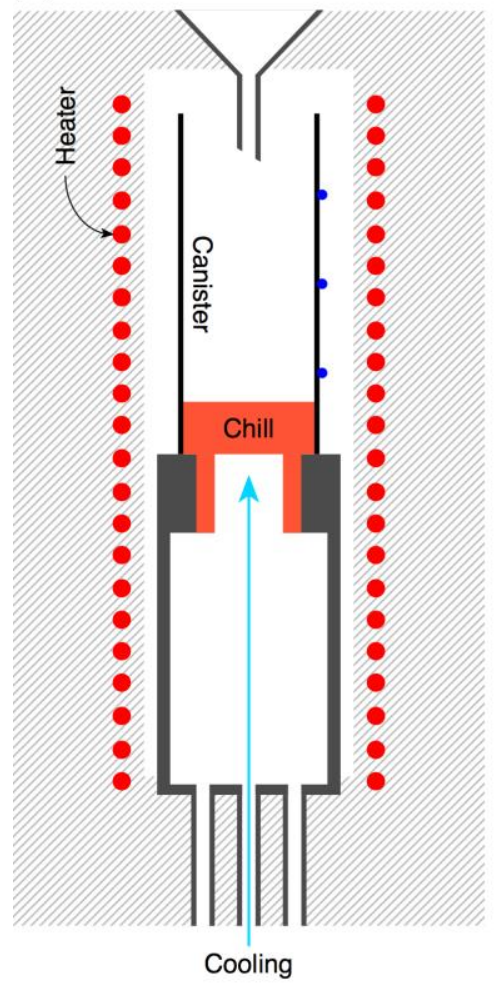

- Thermocouple

Thermal insulation

- Top
---- Middle

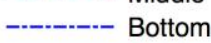

Melting point of $\mathrm{Zn}$

Melting range of $4 \mathrm{Al}-\mathrm{Zn}$ (b)
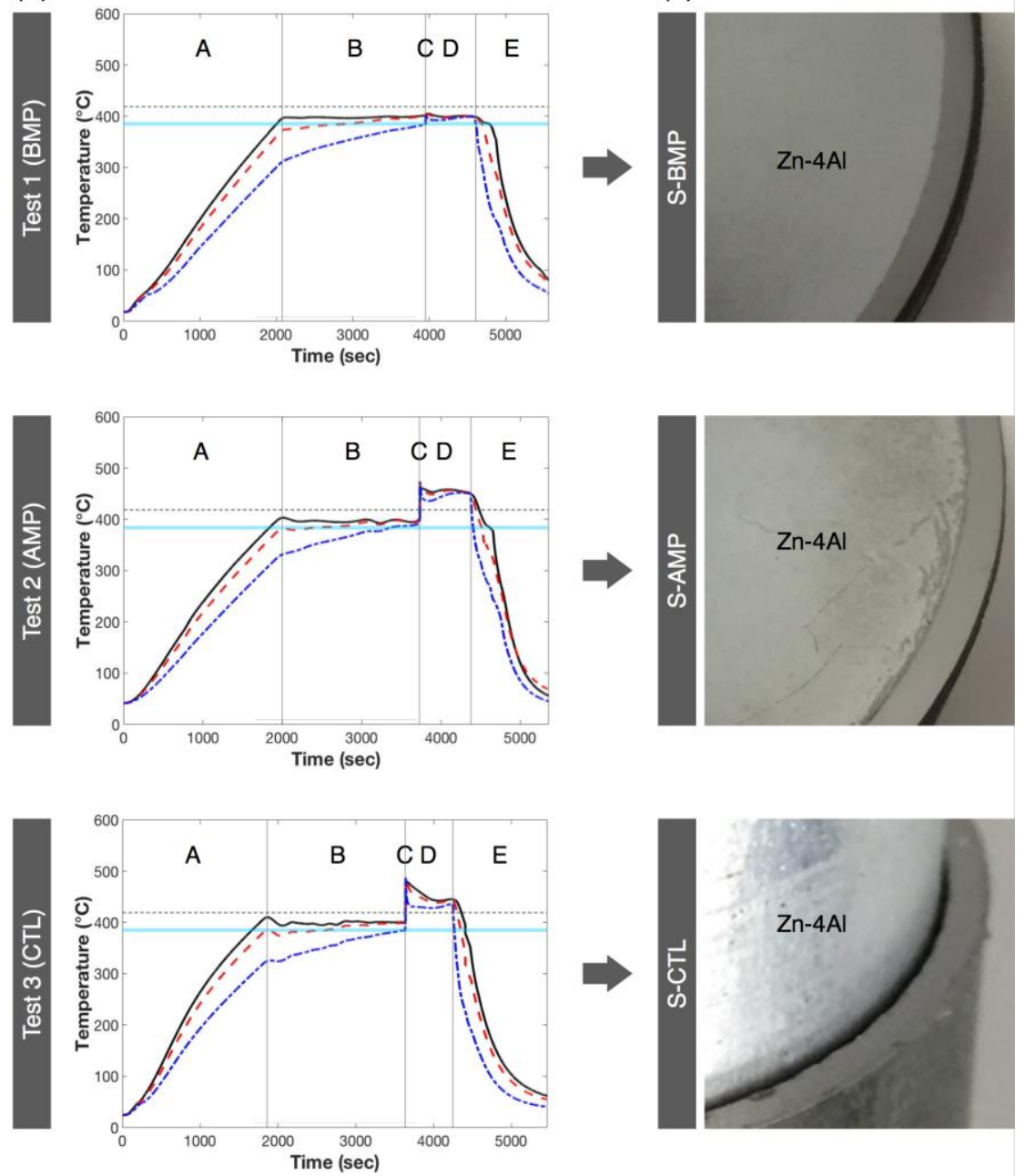

Figure 2. (a) A schematic of the heating/cooling apparatus (not to scale), (b) measured temperature profile from each test, and (c) pictures near the canister/filler interface of the samples from each test. The alphabetical headings in the temperature plots refer to the experimental procedure in section 2.2.2. 


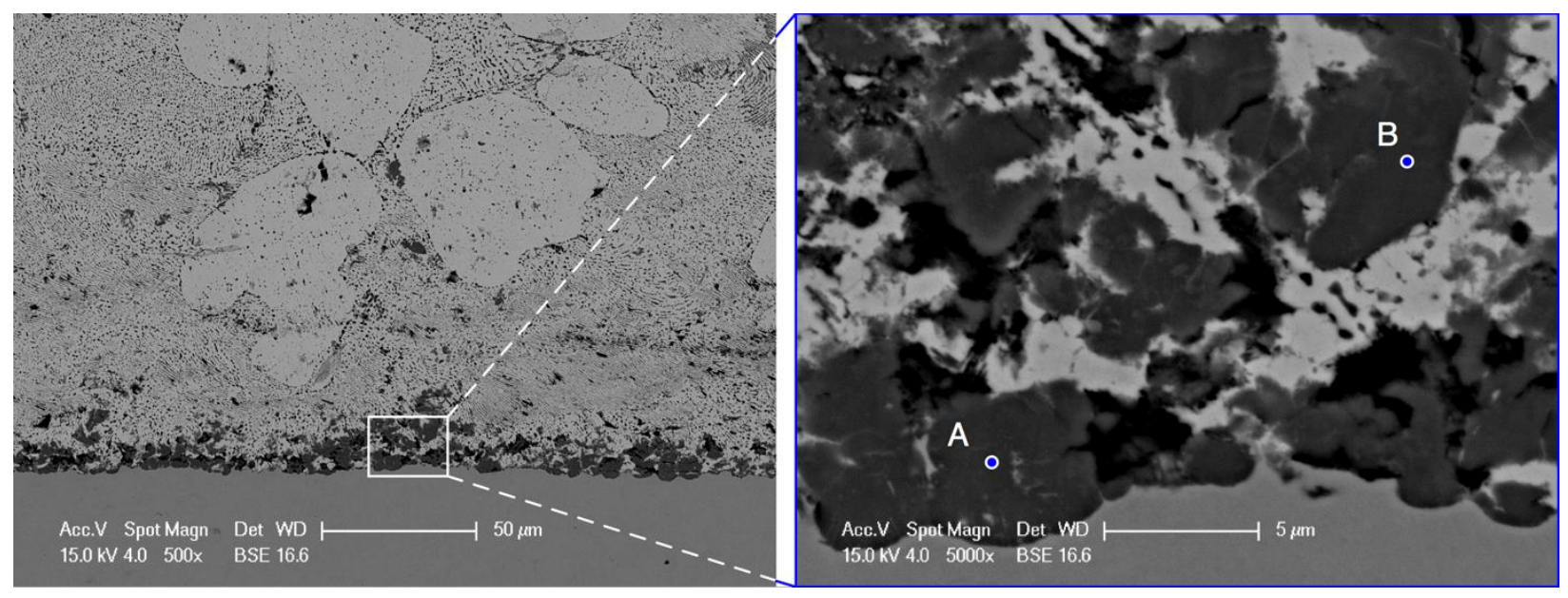

Figure 3. BSEM images near the canister/filler interface of S-BMP. EDX compositional analysis was performed at the marked points. See Table 2 for the results. 

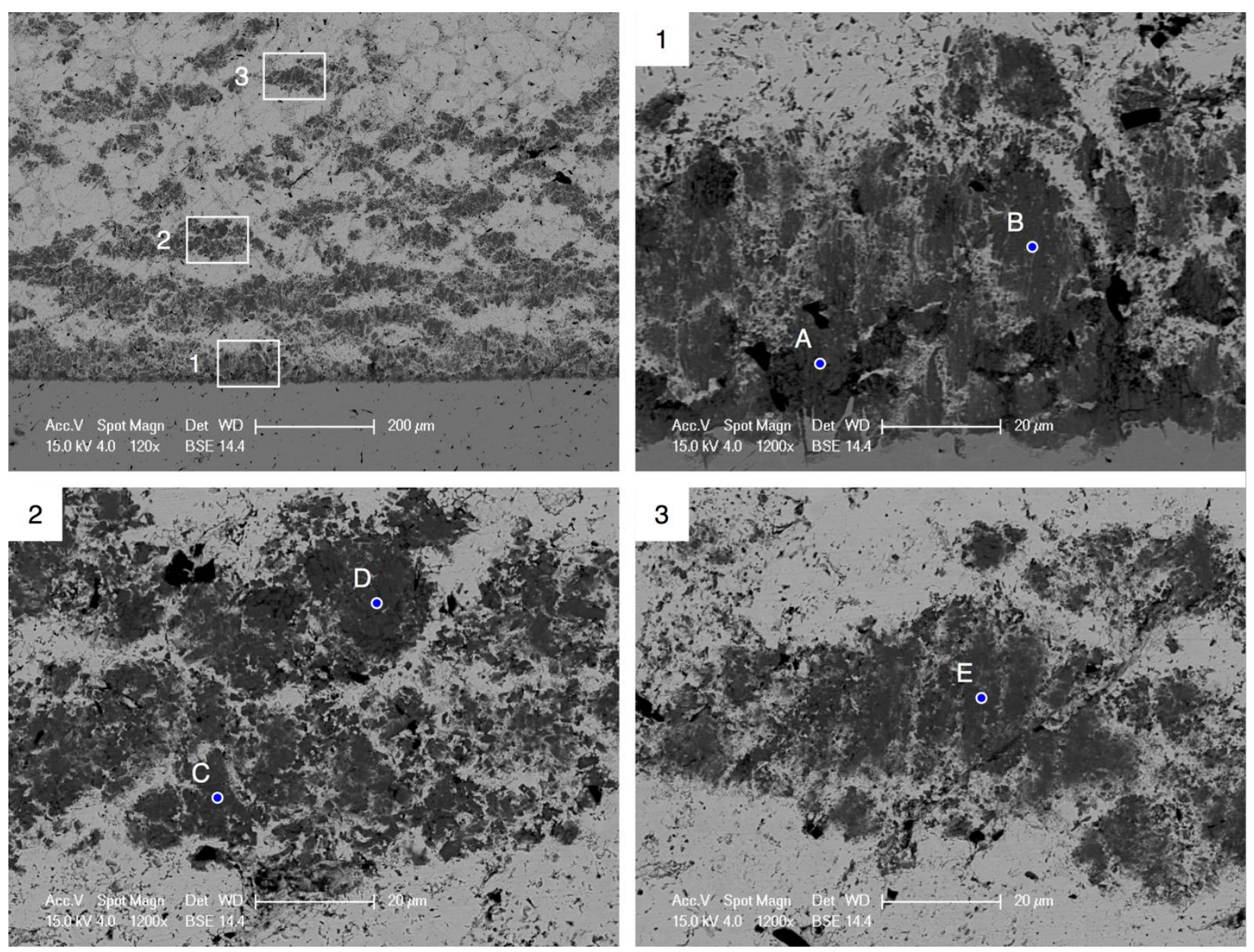

Figure 4. BSEM images near the canister/filler interface of S-AMP. EDX compositional analysis was performed at the marked points. See Table 3 for the results. 


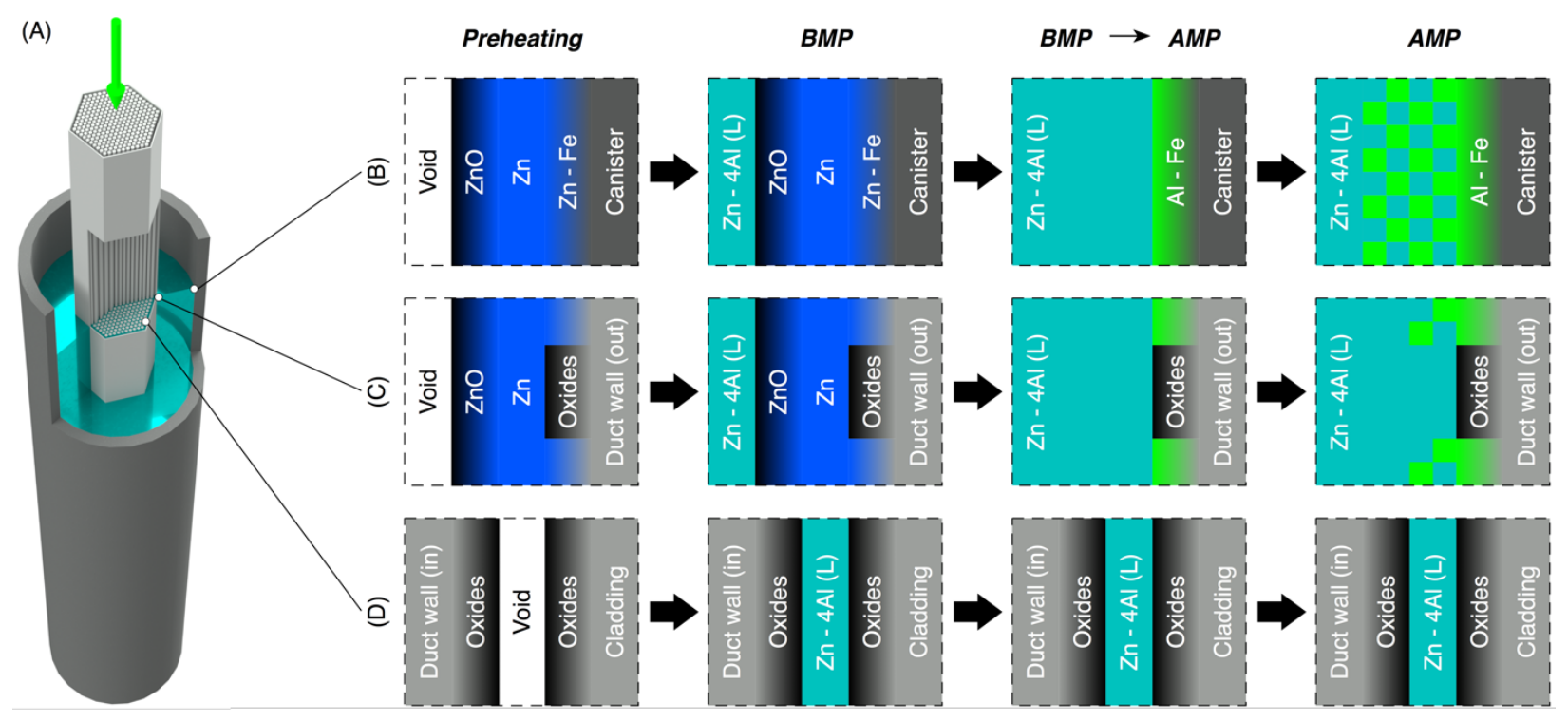

Figure 5. (A) An illustration of emplacing a SNFA into a canister filled with liquid void filler and illustrations of the status near the interface between (B) the void filler and the canister, (C) the void filler and the outer surface of the duct wall, and (D) void filler and the inner surface of the duct wall or the cladding. The layers are not to scale. 


\section{Notes on the Tables and the Figures (when printing)}

All the Tables and Figure 1 are meant to occupy a single column in a two-columned layout.

Figure 2 through Figure 5 are meant to occupy the full width (both columns).

Figure 2 and Figure 5 should be color printed. 


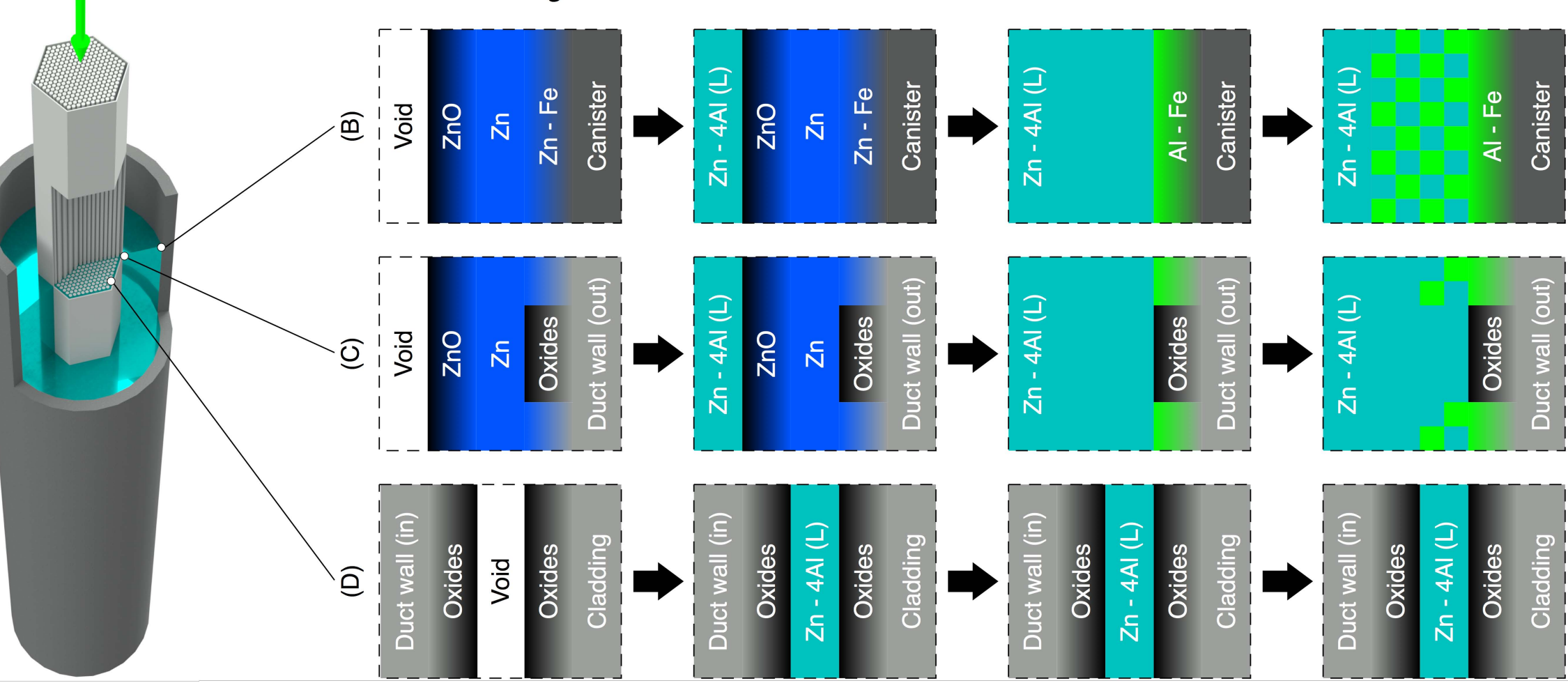

!

O

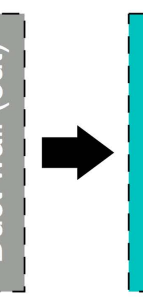

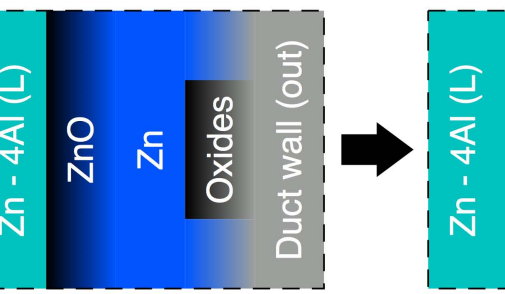

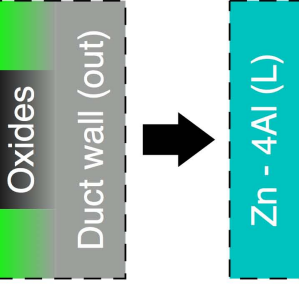

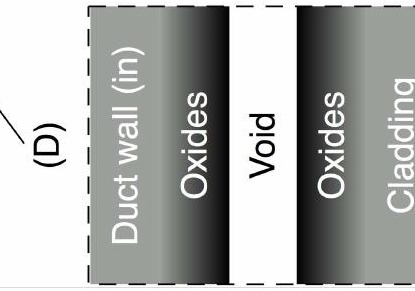

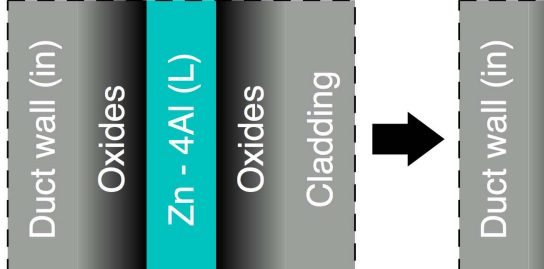

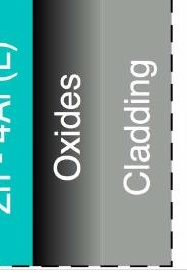

